PAPERS

\title{
Design of dual-band implanted patch antenna system for bio-medical applications
}

\author{
Ahmed Z. A. Zaki ${ }^{1 *}$, Tamer Gaber Abouelnaga ${ }^{2,3}$, \\ Ehab K. I. Hamad ${ }^{4}$, Hala A. Elsadek ${ }^{2}$
}

\begin{abstract}
In this paper, a miniaturized implantable antenna system for biomedical applications is presented. The system consists of almost two similar patch antennas, named internal and external. The internal antenna is implanted inside the body at a depth of $2 \mathrm{~mm}$, and the external antenna is to be attached to the body aligned with the internal one. The antenna system consists of implant-side antenna with dimensions are $10.25 \times 10.25 \times 1.27 \mathrm{~mm}^{3}$, while the external antenna dimensions are $11.1 \times 11.1 \times 1.27 \mathrm{~mm}^{3}$. The proposed antennas designs showed dual resonant frequency on ISM bands (ie, $915 \mathrm{MHz}$ and $2450 \mathrm{MHz}$ ). The computed $-10 \mathrm{~dB}$ bandwidth considering three-layer human phantom demonstrates that a bandwidth of 870 to $970 \mathrm{MHz}$ and 2.38 to $2.47 \mathrm{GHz}$ for internal and external antennas are achieved. The Specific Absorption Rate (SAR) has been considered for health care consideration. The measured and simulated scattering parameters are compared, and good agreements are achieved. The proposed antenna system is simulated and investigated for biomedical applications suitability.

K e ywords: antennas for biomedical applications, implanted antenna, medical implant communication service band (MICS), medical monitoring
\end{abstract}

\section{Introduction}

As a result of medical technology advancements, small size and high-efficiency systems are required to use in biomedical applications $[1,2]$. Biomedical telemetry allows the physiological signals to be measured remotely, either by wire or wireless communication technologies. Recently, the most popular method of telemetry for implantable medical devices was low-frequency inductive link, but the data rate was very low (1- $30 \mathrm{kbps}$ ) with a limited range $(<10 \mathrm{~cm})$ of connection and sensitivity to inter-coil positioning. So to overawe these restrictions, research is now directed toward implanted radio frequency medical devices [3], [4]. Thousands of people around the world depend on implantable medical devices (IMD) to monitor and develop their lives quality. Medical implanted devices that depend on RF-connection are used already till now for a lot of applications, including temperature sensing [4], functional electrical stimulators (FES) [5], pacemakers and cardioverter-defibrillators [6], cochlear [7], bloodglucose sensors [8] and retinal implants [9].

The design of antenna for implantable devices for a medical solution is based on the frequency of operation. Antennas are categorized into low-frequency band antenna, ISM, medical implant communication service band (MICS) antenna, and wireless medical telemetry services band (WMTS) [10].
Low-frequency band inductive links in implanting have long been used for biotelemetry for IMD. MICS frequency band between $402 \mathrm{MHz}$ and $405 \mathrm{MHz}$, allocated by the Federal Communication Committee (FCC) in 1999 and refers to a specification in communication with medical implants [11,12]. The spectrum of $3 \mathrm{MHz}$ allows for 10 channels (bandwidth of $300 \mathrm{kHz}$ each) [4], and it allows bidirectional radio communication between electronic external and implants devices. ISM devices operate in the 902-928 MHz, 2400-2483.5 MHz, and 5725-5850 MHz bands [12]. WMTS bands are (608-614 MHz, 1.395-1.400 $\mathrm{GHz}$ ), and ultra-wideband (UWB) of 3.1-10.6 GHz. There are limitations on the devices that can be implanted in the body. The design of implantable antennas with the appropriate properties still presents a major challenge for special biocompatibility, miniaturization, and safety [13].

Recently, patch antenna receiving major attention in implantable antennas applications because of its flexibility in design and compatibility with most applications [14][15][16], thus allowed to reducing antenna size easily and integrate it into the implantable medical device (IMD) [17].

The maximum power allowed to be incident on human tissue is limited by Specific Absorption Rate (SAR) maximum value [15]. The IEEE standard limits the average SAR for a $1 \mathrm{~g}$ of cube-shaped tissue to less than 1.6 W/kg. And the ICNIRP (International Commission on Non-Ionizing Radiation Protection) basic restrictions

\footnotetext{
${ }^{1}$ Communication Department, Modern Academy for Engineering and Technology, Cairo, Egypt, ${ }^{*}$ Corresponding author: azakaria64@gmail.com, ${ }^{2}$ Microstrip Circuits Department, Electronics Research Institute (ERI), Cairo, Egypt, ${ }^{3}$ Higher Institute of Engineering and Technology, Kafr El-Shiekh, Egypt, ${ }^{4}$ Electrical Engineering Department, Faculty of Engineering, Aswan University, Aswan 81542, Egypt
}

https://doi.org/10.2478/jee-2021-0033, Print (till 2015) ISSN 1335-3632, On-line ISSN 1339-309X (C) This is an open access article licensed under the Creative Commons Attribution-NonCommercial-NoDerivs License (http: //creativecommons.org/licenses/by-nc-nd/3.0/). 


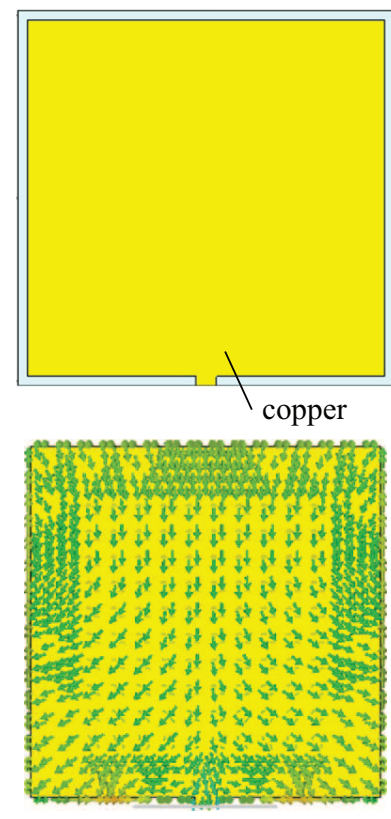

(a)
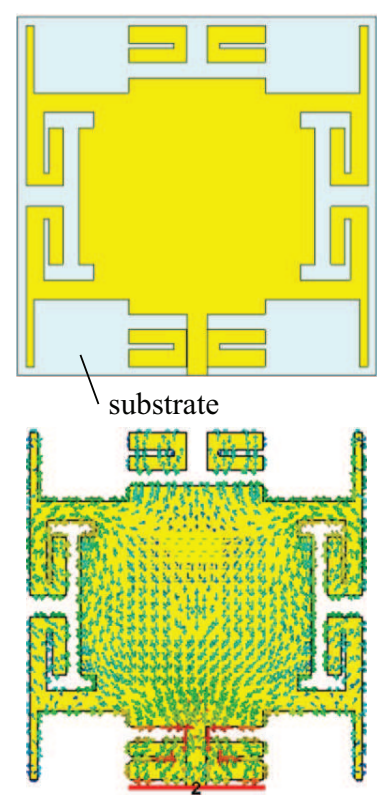

(b)
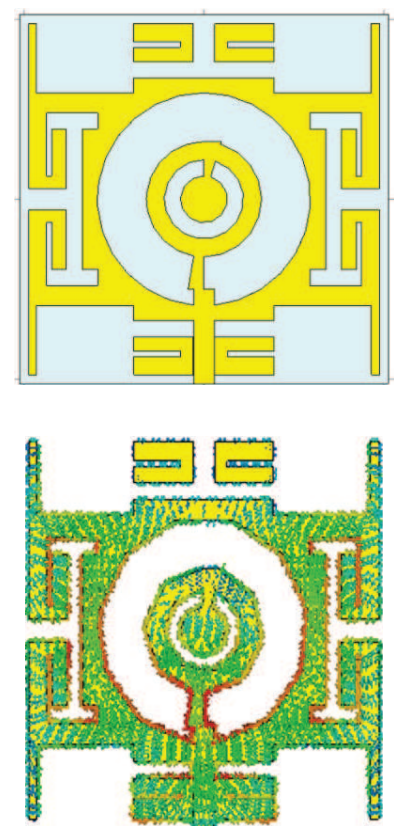

(c)

Fig. 1. Miniaturization process of the proposed internal antenna with the respective current distributions: (a) - case 1, (b) - case 2 , and (c) - case 3

limit the SAR averaged over $10 \mathrm{~g}$ of contiguous tissue to less than $2 \mathrm{~W} / \mathrm{kg},[18-21]$.

In this paper, a novel miniaturized implantable antenna system is proposed for biomedical applications, and it resonates over the ISM bands of $870-970 \mathrm{MHz}$ and 2.40$2.48 \mathrm{GHz}$.

\section{Antenna design and simulation}

\subsection{Antenna design}

The implanted patch antenna system consists of internal and external patch antennas. Internal antenna implants inside the body at a depth of $2 \mathrm{~mm}$ from body skin, while the external antenna is put on body skin. Due to the very limited space allowed, the proposed internal antenna has to be miniaturized to be easily implanted inside the human body with minimum harm. There are several techniques to reduce the size of the antenna, such as using a high permittivity dielectric, increasing the path of current flow over the surface of the patch, short pins and/or patch stacking [4].

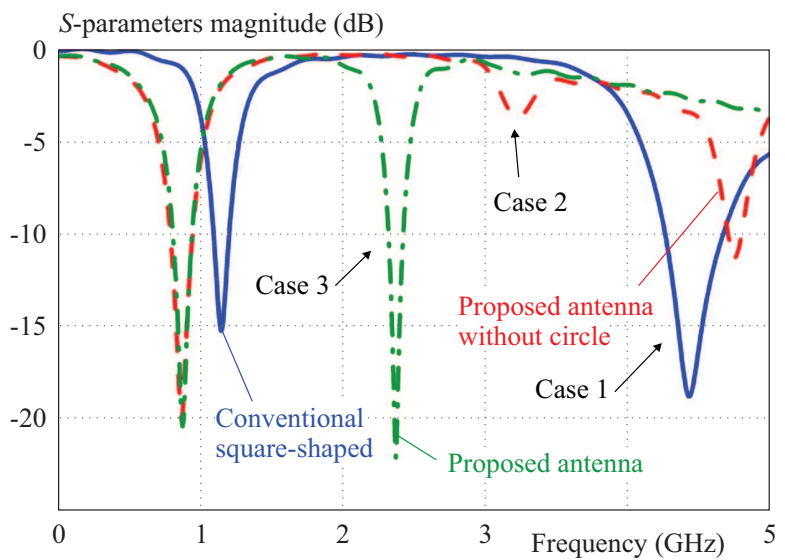

Fig. 2. Simulated $S_{11}$ for miniaturization process of the proposed internal antenna shown in Fig. 1

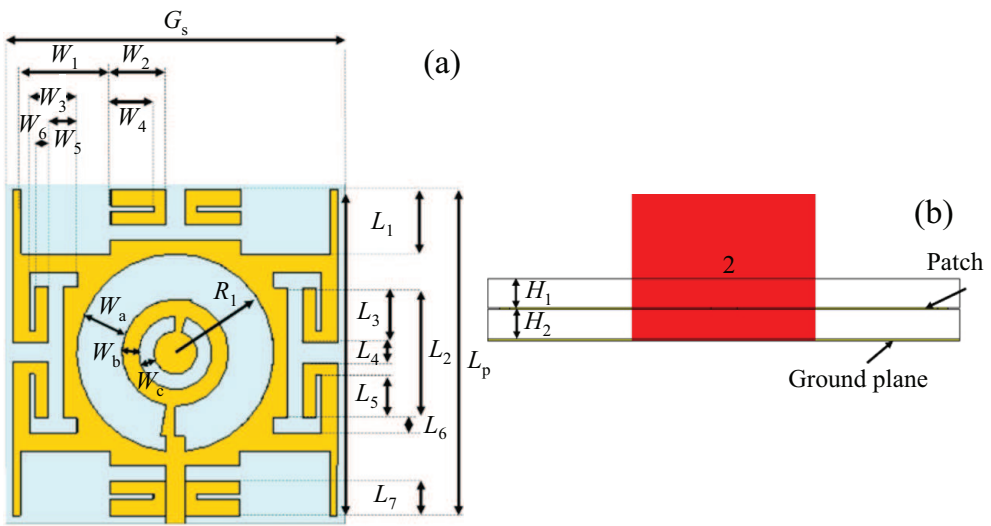

Fig. 3. Geometry of the proposed internal antenna, top and side view 

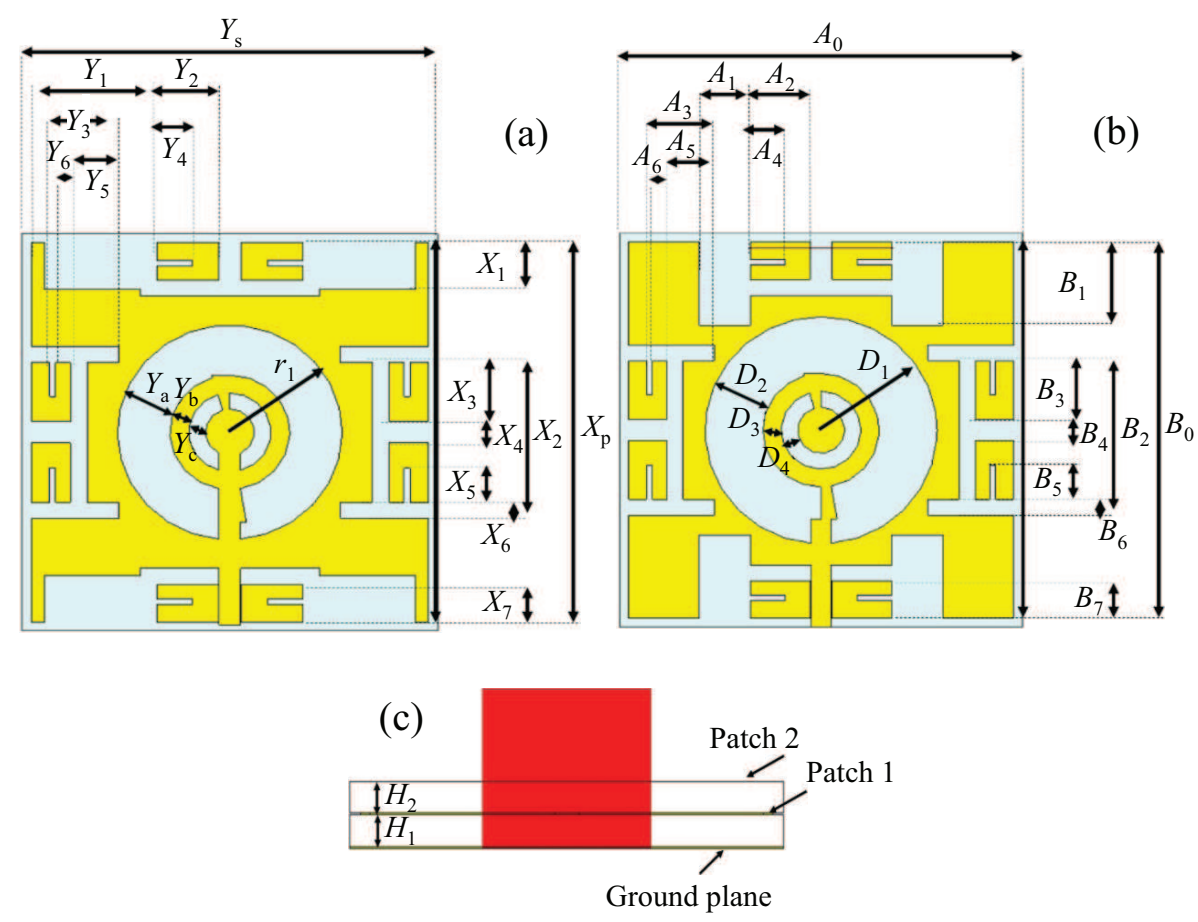

Fig. 4. Geometry of the proposed external antenna: (a) - patch 2, (b) - patch 1, (c) - side view of external antenna

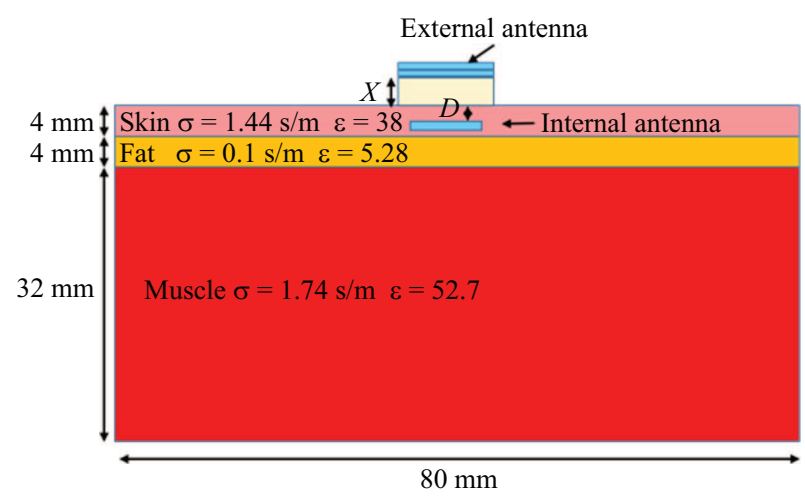

Fig. 5. Three-layer phantom constructed in CST

The electromagnetic performance of the antenna must be maintained acceptable during the antenna downsizing process to implant inside the body. Despite the high permeability of human tissues, which may be the reason for reducing the antenna gain, but it also helped in reducing the physical size of the antenna.

The size reduction process is shown in Fig. 1. Initially, a traditional square patch antenna was used (Case 1) for the proposed internal antenna; the current path is short, resulting in two resonant frequencies at $1.2 \mathrm{GHz}$ and at $4.5 \mathrm{GHz}$, as shown in Fig. 2. So, various slots with different shapes around the edges of the patch are etched out. The current path length increased because of adding slots on the patch, so the lower frequency shifted to $910 \mathrm{MHz}$ (Case 2). Then, circular slots like a split ring resonator (SRR) are created in the center of the patch (case 3) to move down the resonance frequency to 2.45 $\mathrm{GHz}[16]$.

The structures of the proposed antennas (internal and external) are shown in Fig. 3 and Fig. 4, respectively. The proposed antenna prototypes are built on a substrate of Rogers 3210 with 10.2 relative permittivity and 0.003 loss tangent and thickness of $0.635 \mathrm{~mm}$. The internal antenna is covered with another layer of the same substrate to have a total thickness of $1.27 \mathrm{~mm}$. The patch of the internal antenna consists of two metallic slot rings printed on the center of the radiated element, which is surrounded by different shapes of slots, as demonstrated in Fig. 3 .

As shown in Fig. 4, the structure of the external antenna consists of two layers of substrates of the same type from the internal antenna, and each layer consists of two metallic slot rings implemented in the center of the patch. Different rectangular slots are etched surrounding the circular split ring.

The proposed antennas (internal and external) are fed through a $50 \Omega$ microstrip line. To avoid a short circuit of implanted antenna by the human tissues, the internal antenna is enclosed around by biocompatible material with tissues and at the same time to reduce the parasitic coupling of electromagnetic with human tissues. The prototype uses alumina with 9.2 relative permittivity and 0.008 loss tangent, and a thickness of $0.02 \mathrm{~mm}$ to protect the antenna. The optimized dimensions are obtained and listed in Tab. 1. 

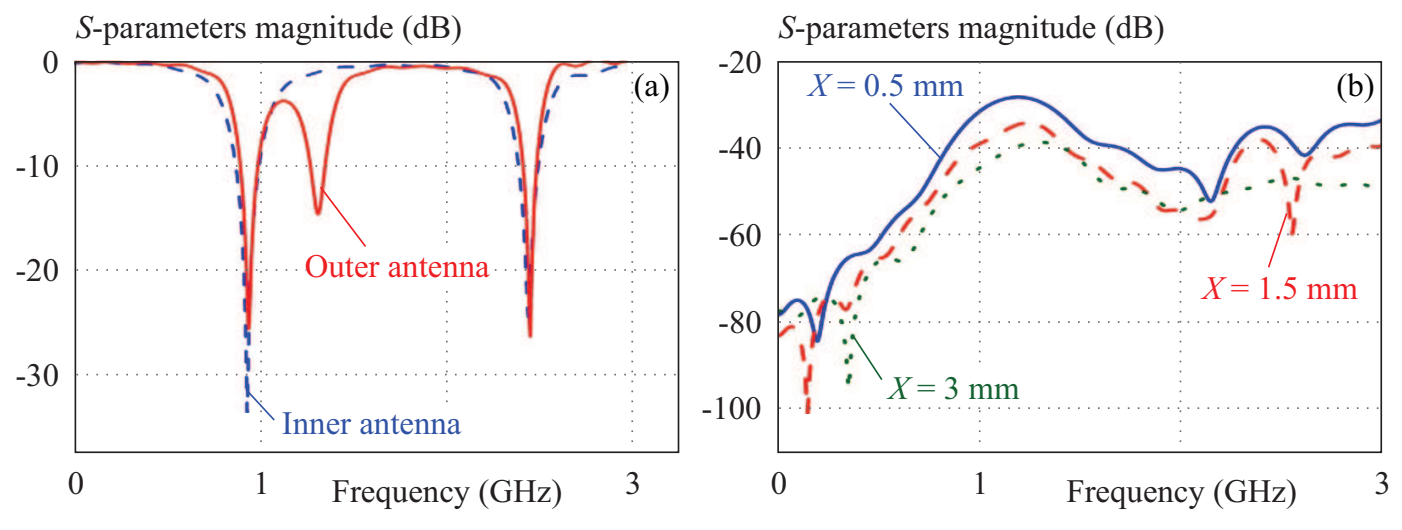

Efficiency $(\mathrm{dB})$

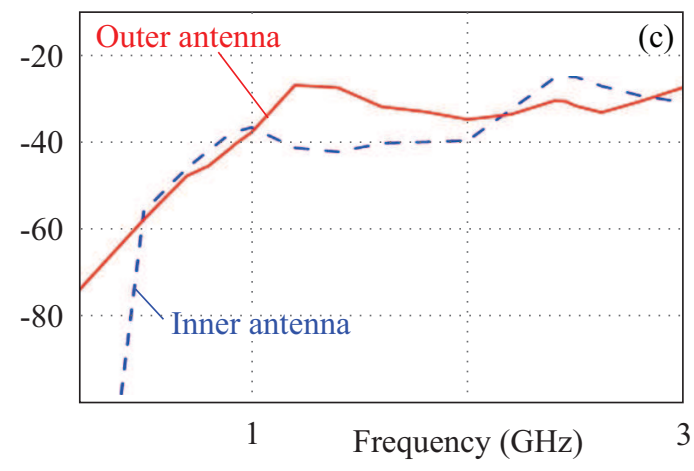

Fig. 6. (a) - simulated $S_{11}$ of the internal and external antenna, (b) -simulated $S_{21}$ of internal and external antenna, and (c) - efficiency of internal and external antenna

Table 1. Optimized internal antenna dimensions (in $\mathrm{mm}$ )

\begin{tabular}{lccccc} 
Dim & Value & Dim & Value & Dim & Value \\
\hline$G_{\mathrm{s}}$ & 10.25 & $L_{6}$ & 0.45 & $W_{5}$ & 0.45 \\
$L_{\mathrm{p}}$ & 9.75 & $L_{7}$ & 1.05 & $W_{6}$ & 0.4 \\
$L_{1}$ & 1.925 & $L_{8}$ & 0.3 & $R_{1}$ & 2.96 \\
$L_{2}$ & 3.9 & $W_{1}$ & 2.7 & $W_{a}$ & 0.4 \\
$L_{3}$ & 1.65 & $W_{2}$ & 1.65 & $W_{b}$ & 0.5 \\
$L_{4}$ & 0.6 & $W_{3}$ & 1.425 & $W_{\mathrm{c}}$ & 0.45 \\
$L_{5}$ & 1.3 & $W_{4}$ & 1.3 & $D$ & 2 \\
\hline
\end{tabular}

Table 2. Optimized external patch 1 antenna dimensions (in $\mathrm{mm}$ )

\begin{tabular}{cccccc} 
Dim & Value & Dim & Value & Dim & Value \\
\hline$B_{0}$ & 11.1 & $A_{6}$ & 0.45 & $B_{5}$ & 1.3 \\
$A_{0}$ & 10.6 & $A_{7}$ & 1.05 & $B_{6}$ & 0.4 \\
$A_{1}$ & 2.35 & $A_{8}$ & 0.3 & $D_{1}$ & 2.96 \\
$A_{2}$ & 3.9 & $B_{1}$ & 1.4 & $D_{2}$ & 0.4 \\
$A_{3}$ & 1.65 & $B_{2}$ & 1.65 & $D_{3}$ & 0.5 \\
$A_{4}$ & 0.6 & $B_{3}$ & 1.86 & $D_{4}$ & 0.45 \\
$A_{5}$ & 0.95 & $B_{4}$ & 0.95 & & \\
\hline
\end{tabular}

To imitate a typical human body, a three-layers phantom has been constructed on a microwave studio (CST) simulator. The human tissue consists of three layers [21$23]$ skin $\left(\sigma=1.44 \mathrm{~s} / \mathrm{m}, \varepsilon_{\mathrm{r}}=38\right)$, fat $\left(\sigma=0.1 \mathrm{~s} / \mathrm{m}, \varepsilon_{\mathrm{r}}=\right.$
$5.28)$, and muscle $\left(\sigma=1.74 \mathrm{~s} / \mathrm{m}, \varepsilon_{\mathrm{r}}=52.7\right)$ layers as illustrated in Fig. 5. The relative permittivity and the conductivity of each layer values have been considered. The proposed internal antenna is inserted in the skin layer at a depth of $2 \mathrm{~mm}$. The external antenna is placed above the phantom and separated from the body by a $0.5 \mathrm{~mm}$ foam layer.

Table 3. Optimized external patch 2 antenna dimensions (in $\mathrm{mm}$ )

\begin{tabular}{lccccc} 
Dim & Value & Dim & Value & Dim & Value \\
\hline$G_{\mathrm{s}}$ & 11.1 & $X_{6}$ & 0.45 & $Y_{5}$ & 1.3 \\
$X_{\mathrm{p}}$ & 10.6 & $X_{7}$ & 1.05 & $Y_{6}$ & 0.56 \\
$X_{1}$ & 1.3 & $X_{8}$ & 0.3 & $a_{1}$ & 3 \\
$X_{2}$ & 3.9 & $Y_{1}$ & 3.35 & $Y_{\mathrm{a}}$ & 0.4 \\
$X_{3}$ & 1.65 & $Y_{2}$ & 1.65 & $Y_{\mathrm{b}}$ & 0.5 \\
$X_{4}$ & 0.6 & $Y_{3}$ & 1.86 & $Y_{\mathrm{c}}$ & 0.45 \\
$X_{5}$ & 0.95 & $Y_{4}$ & 0.95 & $x$ & 0.5 \\
\hline
\end{tabular}

The full system of antennas is simulated and optimized on CST studio. Fig. 6 demonstrates the $S$-parameter of the proposed system. The proposed internal antenna has a $-10 \mathrm{~dB}$ bandwidth of $100 \mathrm{MHz}$ at both frequency bands $(870-970 \mathrm{MHz})$ and $(2.38-2.48 \mathrm{GHz})$. While the external antenna has impedance bandwidths of $86 \mathrm{MHz}$ from 894 to $980 \mathrm{MHz}$ and $80 \mathrm{MHz}$ from 2.4 to $2.48 \mathrm{GHz}$ bands. The external antenna is placed on a layer of foam 

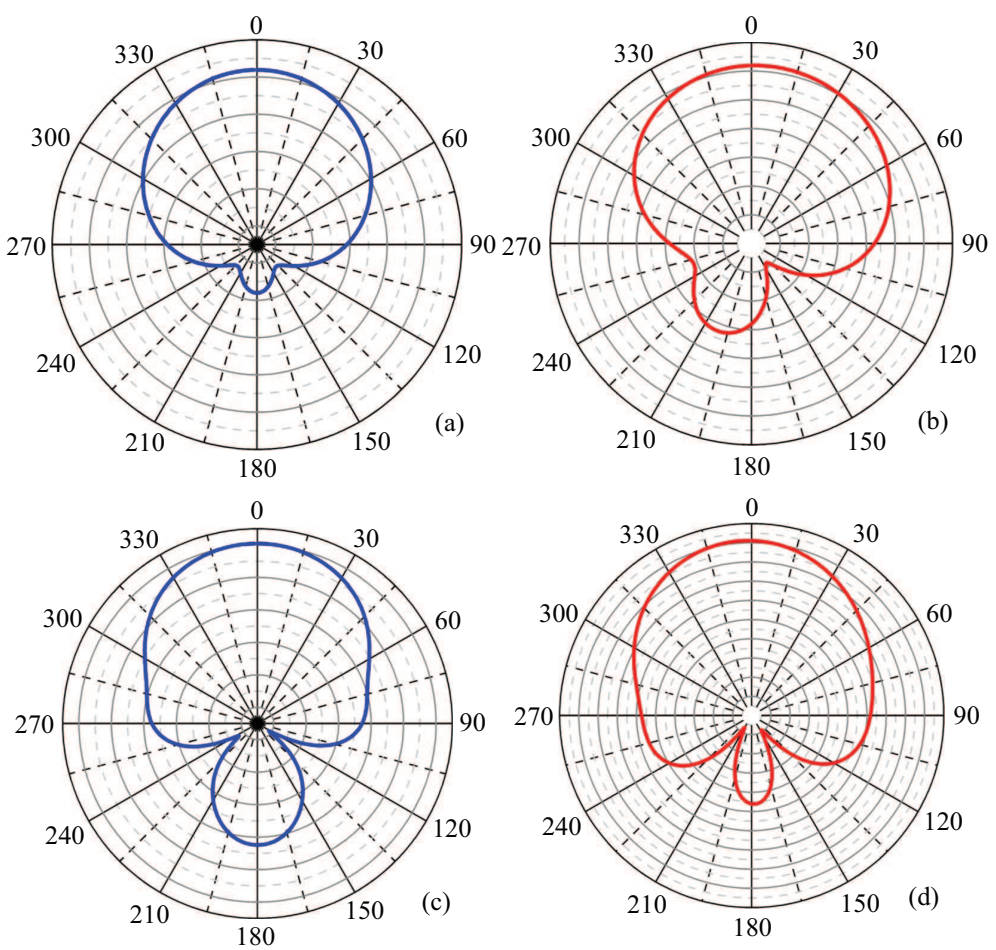

Fig. 7. Radiation patterns of the internal antenna, E and $\mathrm{H}$ plane, respectively at (a) $-910 \mathrm{MHz}$ (b) $-2.45 \mathrm{GHz}$
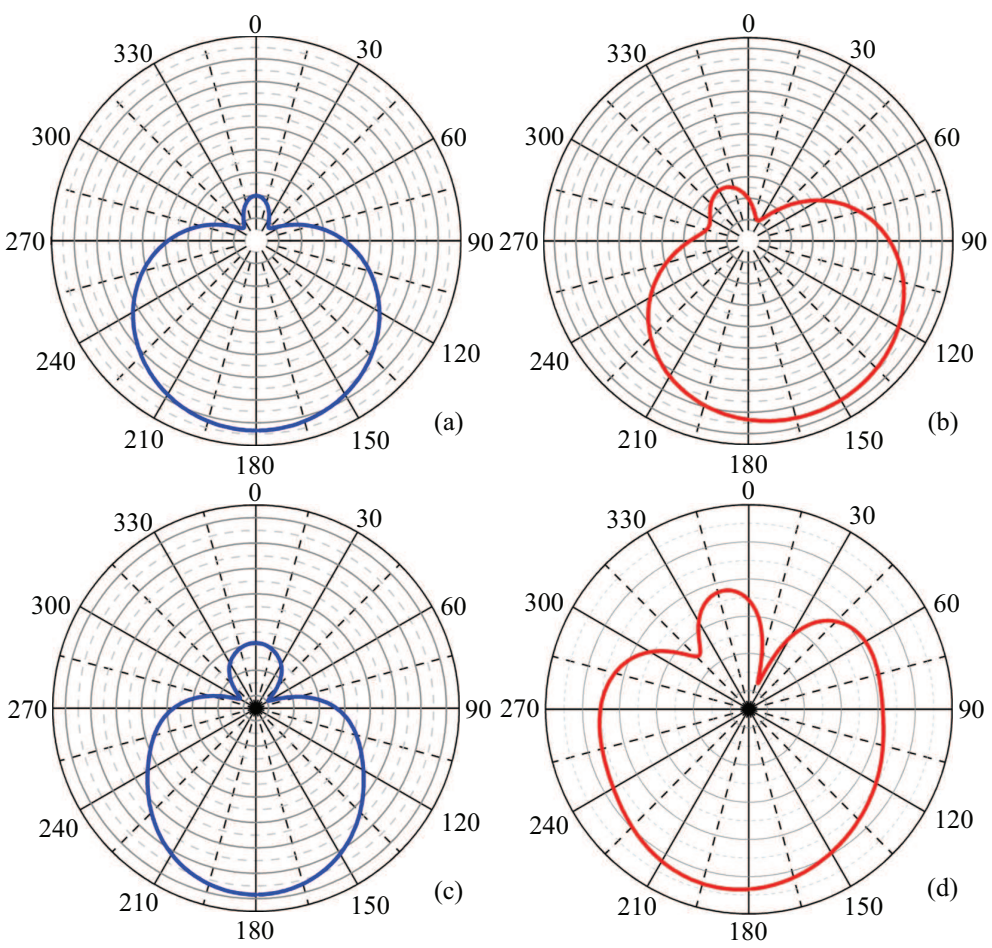

Fig. 8. Radiation patterns of external antenna, E and $\mathrm{H}$ plane, respectively at (a) $-910 \mathrm{MHz}$ (b) $-2.45 \mathrm{GHz}$

to isolate the antenna and to keep the distance of the Fairfield region, which is $2.013 \mathrm{~mm}$ at $2.45 \mathrm{GHz}$ and 0.751 $\mathrm{mm}$ at $915 \mathrm{MHz}$ for the external antenna The radius of the fairfield region can be calculated as, [24]

$$
R=\frac{2 D^{2}}{\lambda}
$$

where $\lambda$ is the wavelength and $D$ is the largest dimension of the antenna. The coupling between the internal and external antennas is directly affected by several factors, such as the separation between the antennas (internal and external) and the medium surrounding the internal antenna. The coupling value varies due to changes in the $\mathrm{x}$ values (foam thickness), as shown in Fig. 6 (b). It is 


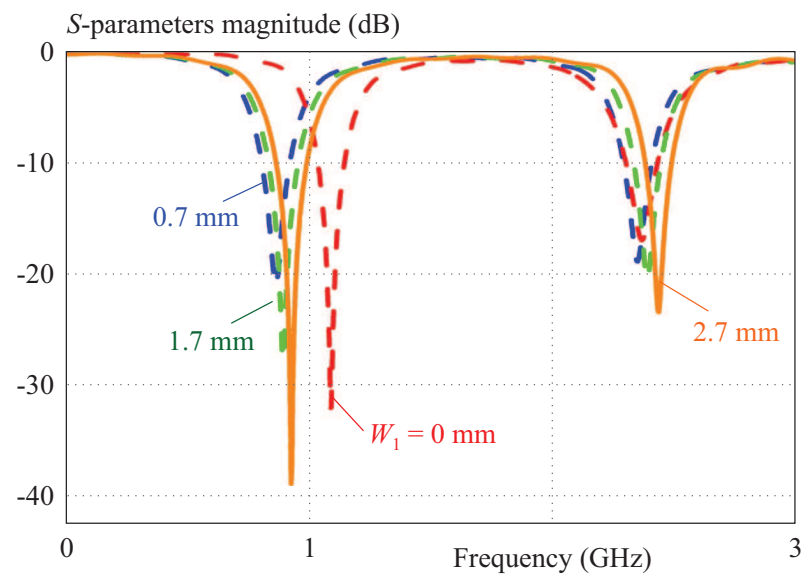

Fig. 9. Effect of varying width $\left(W_{1}\right)$ values on $S$-parameters of the internal antenna

found that the coupling value is better when the external antenna is closer to the skin. The coupling value varies with the frequency, so coupling was obtained of $-33 \mathrm{~dB}$ at $910 \mathrm{MHz}$ and $-35.5 \mathrm{~dB}$ at $2.45 \mathrm{GHz}$. The coupling was affected due to the emission of the signal through the skin layer, which is the lossy material that causes significant signal attenuation [25]-[28].

Radiation patterns, given in Fig. 7 and Fig. 8 are almost directional. The internal and external antennas are placed in the $x-y$ plane so that the direction of the radiation pattern is mainly in the $z$-axis direction. The maximum value of the E-field of the internal antenna is obtained at 0 degrees, as shown in Fig. 7, and at 180 degrees, as shown in Fig. 8. Because the electrically small size of internal $(0.08 \lambda)$ and human tissues cause high dissipation in gain, so negative $-19.8 \mathrm{dBi}$ peak gain has been obtained [17].

A $3 \mathrm{~dB}$ beamwidth of internal antenna is 140 degrees at $910 \mathrm{MHz}$ band with $-6.9 \mathrm{~dB}$ side lobe level as shown in Fig. 7 (a) and 80 degrees at $2.45 \mathrm{GHz}$ band with $-11.7 \mathrm{~dB}$ sidelobe level.

While the $3 \mathrm{~dB}$ beamwidth of the external antenna is about 146 degrees at $910 \mathrm{MHz}$ with $-6.4 \mathrm{~dB}$ side lobe level as shown in Fig. 8(a) and about 88 degrees at 2.45 $\mathrm{GHz}$ band with $-11 \mathrm{~dB}$ side lobe level

\subsection{SAR calculations}

There are essential issues for patient safety to limit the maximum power of the implantable antenna, so the dosimetric of allowed power is measured according to international guidelines as stated in the introduction. The maximum specific absorption rate at $910 \mathrm{MHz}$ is $33 \mathrm{~W} / \mathrm{kg}$ and at $2.45 \mathrm{GHz}$ and is $32 \mathrm{~W} / \mathrm{kg}$ at $0.5 \mathrm{~W}$ input power delivered to the internal antenna so the input power must be reduced to meet SAR limits, so the delivered power to the proposed antenna must not increase more than 30 $\mathrm{mW}(14.7 \mathrm{dBm})$, [18-19]. The SAR is defined by[29]

$$
S A R=\frac{\sigma|E|^{2}}{\rho_{\mathrm{den}}},
$$

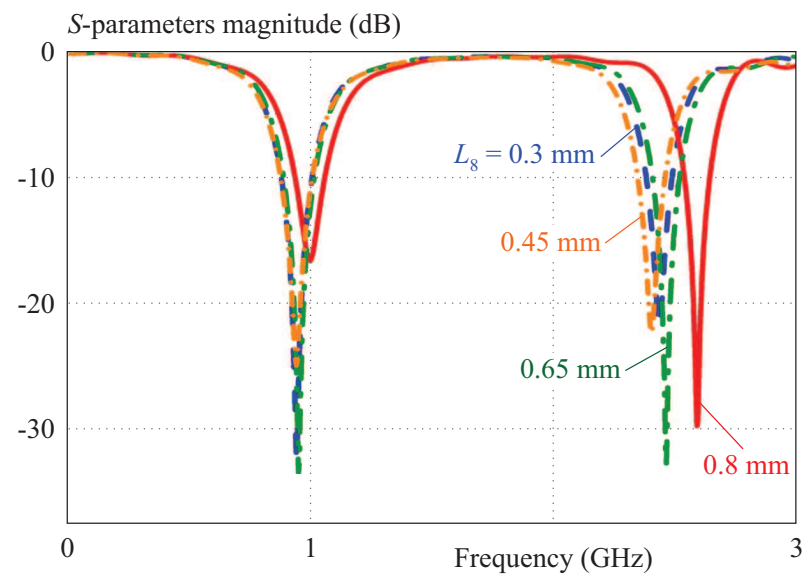

Fig. 10. Effect of varying length $\left(L_{8}\right)$ values on $S$-parameters of the internal antenna

where $\sigma$ is the conductivity of human tissue, $E$ is the intensity of the electric field, and $\rho_{\text {den }}$ is the density of human tissue. At present, there is no experimental method for measuring SAR, so a CST studio as a 3D fullwave simulator has been used to determine the maximum power of the RF radiation to achieve the safety standards.

\subsection{Parametric studies}

Many parameters affect the performance of the proposed internal antenna, so several factors are analyzed to optimize the design. The most effective parameters on the antenna characteristics, such as resonance frequencies are studied to find out their changing effects on the antenna performance, as illustrated in the following figures.

The simulation results depicted in Fig. 9 to Fig. 11 show that the main parameters that affect the resonant frequencies are the radius $R_{1}$, slot width $W_{1}$, and the length $L_{8}$, which play a vital role in the distributions of surface current and also in matching impedance. The higher resonant frequency is fully controlled by change $R_{1}$.

\subsection{Link budget for wireless communication}

The way to quantifying the performance of communication link is called link budget [30]. There are three main factors determining the received power in wireless communication: Tx power, Tx antenna gain, and Rx antenna gain. The difference between the minimum received signal level (required $\mathrm{C} / \mathrm{No}$ ) and the actual received power (link $\mathrm{C} / \mathrm{No}$ ) is called the link margin. to estimate the range between the proposed antenna and a receiver outside the body, The link margin must be positive, and it can calculate by [17]

$$
\operatorname{LM}(\mathrm{dB})=\operatorname{link} \frac{C}{N_{0}}, \quad \text { - required } \frac{C}{N_{0}},
$$

$$
\operatorname{Link} \frac{C}{N_{0}}=P_{\mathrm{t}}-2 L_{\mathrm{feed}}+G_{\mathrm{t}}-L_{\mathrm{f}}-L_{\mathrm{a}}+G_{\mathrm{r}}+N_{0},
$$




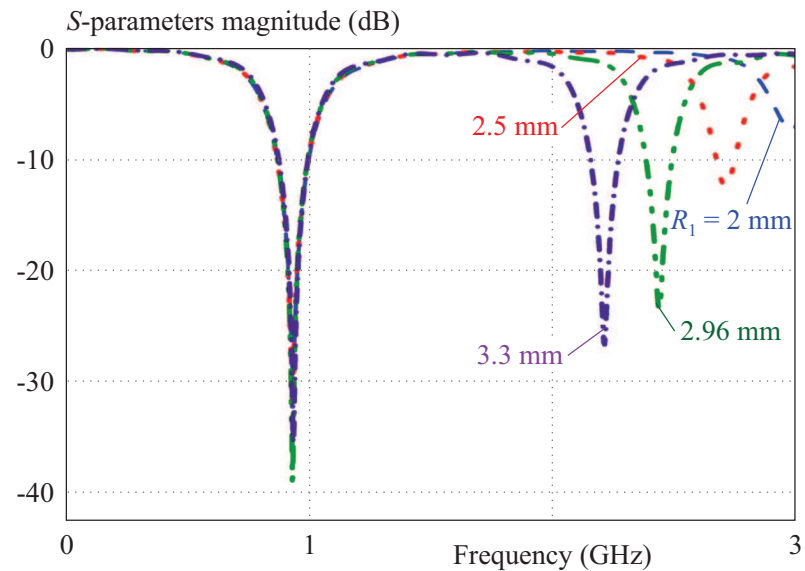

Fig. 11. Effect of varying radius $\left(R_{1}\right)$ values on $S$-parameters of the internal antenna

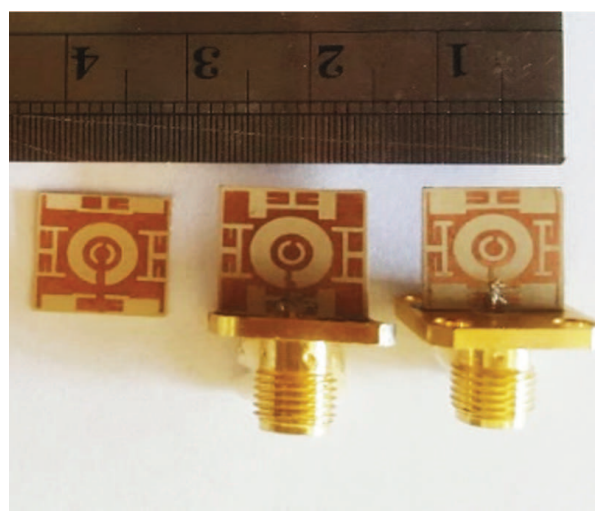

Fig. 13. Photos of the fabricated antenna prototype

$$
\text { Required } \frac{C}{N_{0}}=\frac{E_{\mathrm{b}}}{N_{0}}+10 \log \left(B_{\mathrm{r}}\right)-G_{\mathrm{c}}+G_{\mathrm{d}},
$$

where $P_{\mathrm{t}}$ is Tx Power, $L_{\text {feed }}$ is feeding loss, $G_{\mathrm{t}}$ is gain of the transmitter antenna, $L_{\mathrm{f}}$ is total propagation loss, $L_{\mathrm{a}}$ is air propagation loss, $G_{\mathrm{r}}$ is gain of received antenna $N_{0}$ noise power density, $E_{\mathrm{b}} / N_{0}$ normalized signal-to-noise, $B_{\mathrm{r}}$ is bit rate $G_{\mathrm{c}}$ coding gain $G_{\mathrm{d}}$ fixing deterioration.

The gain of the received antenna is $-27.95 \mathrm{dBi}$, and the again of the transmitter antenna is $-19.8 \mathrm{dBi}$, and a good matching is assumed. The feeding power to implanted antenna is $-41 \mathrm{~dB}$ to investigate the safety required mentioned above. The values of other related parameters used to calculate the LM are chosen to be identical to those reported in the relevant literature[30]

As illustrated in Fig. 12, the maximum range to communicate between $\mathrm{Tx}$ antenna and $\mathrm{Rx}$ antenna can be reached within 8 meters for LM values greater than $0 \mathrm{~dB}$.

\section{Experimental results and analysis}

For validation purposes of the simulated results, experimental measurements are performed here in two cases:

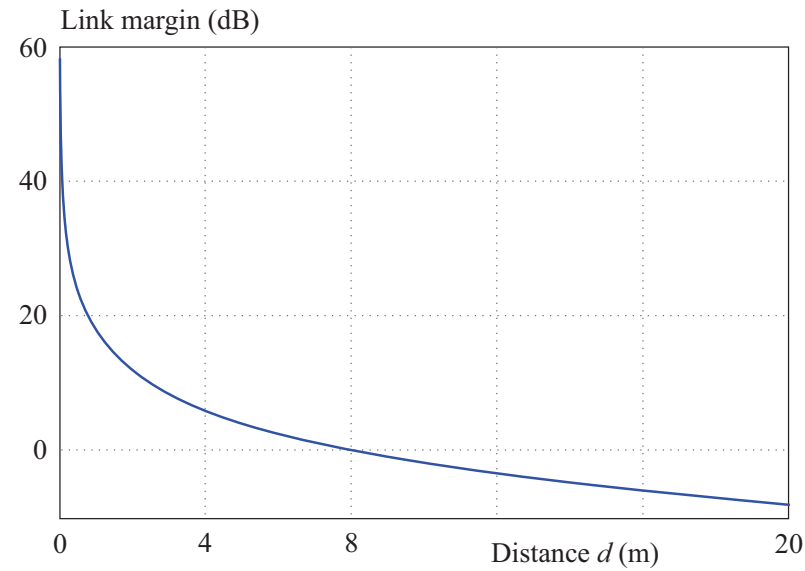

Fig. 12. Calculated link margin of the proposed internal antenna

(a) - on air, and (b) - in fresh streaky meat. The fabricated prototype and experimental setup images are shown in Fig. 13.

As shown in Fig. 14, a comparison of simulated and measured reflection coefficients of internal and external antennas show that they are agreed well. The slight frequency shifting could be caused by the unexpected fabrication tolerance and soldering roughness.

Due to the difficulty in obtaining alumina, which prevents antenna from direct contact to tissues and measurements were performed without it. So, the proposed antenna under test is in direct contact with the fresh streaky meat, and this did not help the antenna resonate at the lower frequency band of $910 \mathrm{MHz}$ as illustrated in Fig. 15, the comparison between simulated and measured reflection coefficients of the implanted internal antenna without the alumina layer.

\section{Conclusions}

In this article, an efficient system consisting of internal and external antennas operates at the ISM band is presented. A novel single-fed miniaturized dual-band implantable antenna system for biomedical applications has been introduced. Both the internal and external antennas are designed to have a simple patch structure that can be easily used in biomedical applications. The proposed antennas are miniaturized to harmless implant inside the human body. The miniaturization process has been presented in this paper. For the optimization process of the implantable antenna, the CST microwave studio simulator with homogeneous human tissues was used. The implanted proposed antenna has dimensions of $10.25 \times 10.25 \times 1.27 \mathrm{~mm}^{3}$, while the external antenna has dimensions of $11.1 \times 11.1 \times 1.27 \mathrm{~mm}^{3}$. The coupling between the internal and external antennas has been studied, and its results are widely accepted. The radiation patterns are presented, and it found that the radiation of the implanted antenna is mainly outside the body, which 
$S$-parameters magnitude $(\mathrm{dB})$

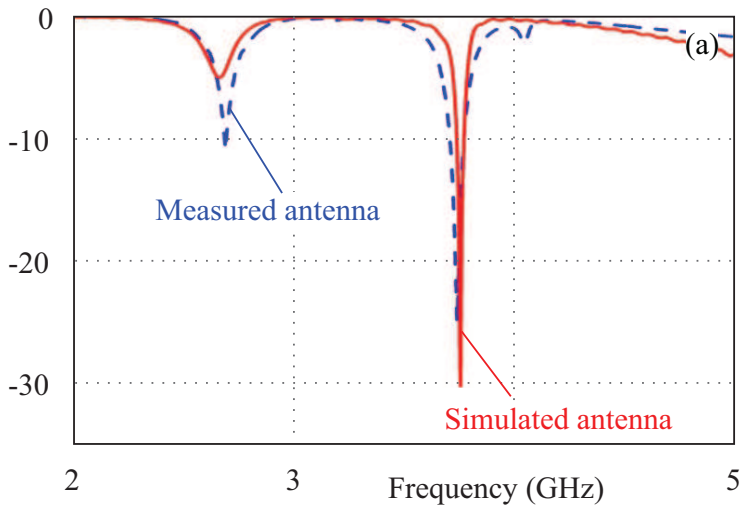

$S$-parameters magnitude $(\mathrm{dB})$

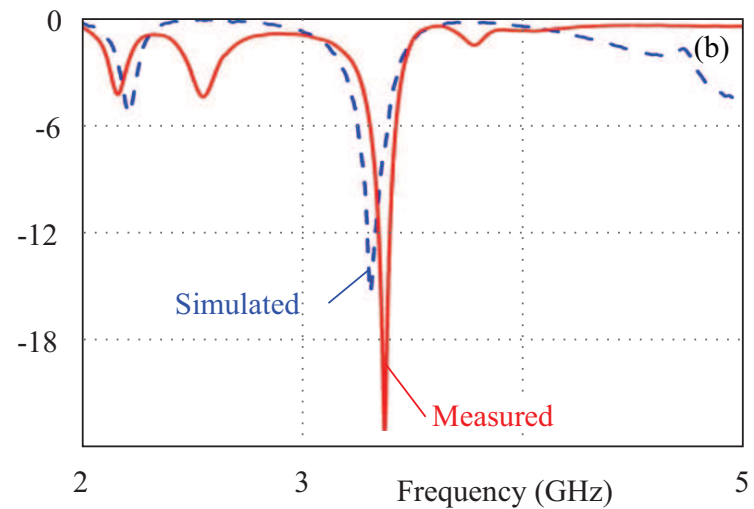

Fig. 14. Simulated and measured reflection coefficient of the presented antenna on air (a) - internal and (b) - external antenna

$S$-parameters magnitude $(\mathrm{dB})$

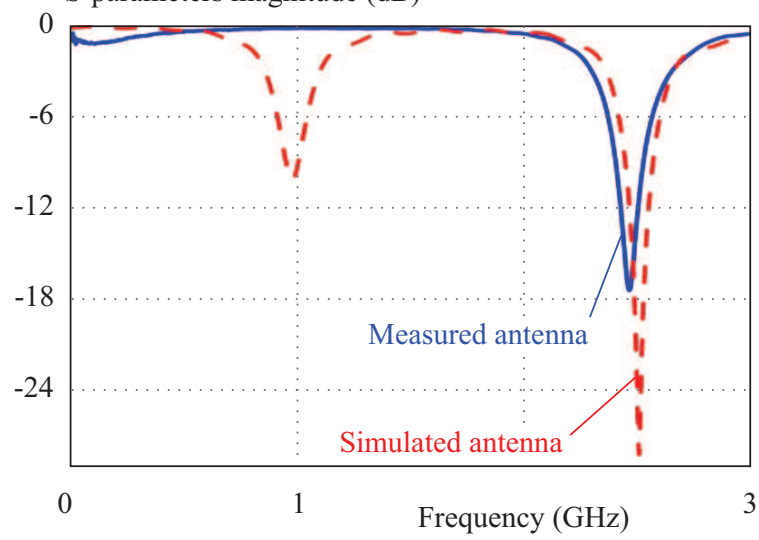

Fig. 15. Simulated and measured reflection coefficient of implanted internal antenna

makes it suitable for biomedical applications. A parametric study was performed to determine the main factors affecting the resonant frequencies. The fabricated prototypes were performed in two cases (a) - on-air and (b) in fresh streaky meat. A good agreement is obtained between simulation and measurement results for the reflection coefficients of both antennas. The measured bandwidth is wide enough to cover the whole MICS band. For human health safety, the SAR has been evaluated.

\section{REFERENCES}

[1] A. Kiourti, K. A. Psathas, J. R. Costa, C. A. Fernandes, and K. S. Nikita, "Dual-band implantable antennas for medical telemetry: A fast design methodology and validation for intra-cranial pressure monitoring", Prog. Electromagn. Res., vol. 141, no. May, pp. 161-183, 2013, doi: 10.2528/PIER13051706.

[2] T. G. Abouelnaga and A. F. Desouky, "UWB Antenna with All Band Suitable Radiation Pattern for Breast Cancer Detection", Int. J. Eng. Technol., vol. 9, no. 2, pp. 720-737, 2017, doi: $10.21817 / \mathrm{ijet} / 2017 / \mathrm{v} 9 \mathrm{i} 2 / 170902082$.

[3] W. Greatbatch and C. F. Holmes, "History of implantable devices", IEEE Eng. Med. Biol. Mag., vol. 10, no. 3, pp. 38-41, 2002, doi: $10.1109 / 51.84185$.
[4] A. Kiourti and K. S. Nikita, "A review of implantable patch antennas for biomedical telemetry: Challenges and solutions", IEEE Antennas Propag. Mag., vol. 54, no. 3, pp. 210-228, 2012, doi: 10.1109/MAP.2012.6293992.

[5] K. Kato, H. Matsuki, F. Sato, T. Satoh, and N. Handa, "Duplex communicable implanted antenna for magnetic direct feeding method: Functional electrical stimulation", J. Appl. Phys., vol. 105, no. 7, pp. 2007-2010, 2009, doi: 10.1063/1.3068642.

[6] D. Wessels, "Implantable pacemakers and defibrillators: Device overview \& EMI considerations", IEEE Int. Symp. Electromagn. Compat., vol. 2, pp. 911-915, 2002, doi: 10.1109/isemc.2002.1032 815 .

[7] A. Vorobyov, C. Hennemann, A. Vasylchenko, J. D. Decotignie, and J. Baumgartner, "Folded loop antenna as a promissing solution for a cochlear implant", 8 th Eur. Conf. Antennas Propagation, EuCAP 2014, no. EuCAP, pp. 1735-1738, 2014, doi: 10.1109/EuCAP.2014.6902127.

[8] M. C. Shults, R. K. Rhodes, S. J. Updike, B. J. Gilligan, and W. N. Reining, "A Telemetry-Instrumentation System for Monitoring Multiple Subcutaneously Implanted Glucose Sensors", IEEE Trans. Biomed. Eng., vol. 41, no. 10, pp. 937-942, 1994, doi: $10.1109 / 10.324525$.

[9] K. Gosalia, G. Lazzi, and M. Humayun, "Investigation of a microwave data telemetry link for a retinal prosthesis", IEEE Trans. Microw. Theory Tech., vol. 52, no. 8 II, pp. 1925-1933, 2004, doi: 10.1109/TMTT.2004.832007.

[10] D. H. Jiang and Z. Hao, ed. Werner, Electromagnetics of body area networks: antennas, propagation, and $R F$ systems Wiley-IEEE Press, 2016.

[11] N. Vidal, S. Curto, J. M. Lopez Villegas, J. Sieiro, and F. M. Ramos, "Detuning study of implantable antennas inside the human body", Prog. Electromagn. Res., vol. 124, no. January, pp. 265-283, 2012, doi: 10.2528/PIER11120515.

[12] 64 Rules Regulations, "Medical Implant Communications Service (MICS) Federal Register", Fed. Regist., vol. 75, no. 180, pp. 56928-56935, 2010, doi: 10.1016/0196-335 × (80)90058-8.

[13] P. Valdastri, A. Menciassi, A. Arena, C. Caccamo, and P. Dario, "An implantable telemetry platform system for in vivo monitoring of physiological parameters", IEEE Trans. Inf. Technol. Biomed., vol. 8, no. 3, pp. 271-278, 2004, doi: 10.1109/TITB.2004. 834389 .

[14] H. A. Elsadek, E. A. Abdallah, D. M. Elsheakh, and H. B. E. D. El-Shaarawy, "Microstrip antennas: Future trends and new applications", Int. J. Antennas Propag., vol. 2013, pp. 2013-2014, 2013, doi: $10.1155 / 2013 / 890764$.

[15] R. Matthes, J. H. Bernhardt, and A. F. McKinlay, International Commission on Non-Ionizing Radiation Protection.,,, vol. 74, no. 4. 1999. 
[16] W. Ali, E. Hamad, M. Bassiuny, and M. Hamdallah, "Complementary split ring resonator based triple band microstrip antenna for WLAN/WiMAX applications", Radioengineering, vol. 26, no. 1, pp. 78-84, 2017, doi: 10.13164/re.2017.0078.

[17] X. Y. Liu, Z. T. Wu, Y. Fan, and E. M. Tentzeris, "A Miniaturized CSRR Loaded Wide-Beamwidth Circularly Polarized Implantable Antenna for Subcutaneous Real-Time Glucose Monitoring", IEEE Antennas Wirel. Propag. Lett., vol. 16, no. c, pp. 577-580, 2017, doi: 10.1109/LAWP.2016.2590477.

[18] S. Das and D. Mitra, "A compact wideband flexible implantable slot antenna design with enhanced gain", IEEE Trans. Antennas Propag., vol. 66, no. 8, pp. 4309-4314, 2018, doi: 10.1109/TAP.20 18.2836463

[19] R. Li and S. Xiao, "Compact slotted semi-circular antenna for implantable medical devices", Electron. Lett., vol. 50, no. 23, pp. 1675-1677, 2014, doi: 10.1049/el.2014.3371.

[20] K. Guido and A. Kiourti, "Wireless Wearables and Implants: A Dosimetry Review", Bioelectromagnetics, vol. 41, no. 1, pp. 3-20, 2020, doi: 10.1002/bem.22240.

[21] G. Singh and J. Kaur, "Skin and brain implantable inset-fed antenna at ISM band for wireless biotelemetry applications", Microw. Opt. Technol. Lett., vol. 63, no. 2, pp. 510-515, 2021, doi: 10.1002/mop.32603.

[22] R. Li, Y. X. Guo, B. Zhang, and G. Du, "A Miniaturized Circularly Polarized Implantable Annular-Ring Antenna", IEEE Antennas Wirel. Propag. Lett., vol. 16, no. c, pp. 2566-2569, 2017, doi: 10.1109/LAWP.2017.2734246.

[23] T. Karacolak, A. Z. Hood, and E. Topsakal, "Design of a dual-band implantable antenna and development of skin mimicking gels for continuous glucose monitoring", IEEE Trans. Microw. Theory Tech., vol. 56, no. 4, pp. 1001-1008, 2008, doi: 10.1109/TMTT.20 08.919373.

[24] Constantine A. Balanis, Antenna Theory: Analysis and Design, 3 rd ed. Wiely, 2010.
25] A. Sharma, E. Kampianakis, and M. S. Reynolds, "A Dual-Band HF and UHF Antenna System for Implanted Neural Recording and Stimulation Devices", IEEE Antennas Wirel. Propag. Lett., vol. 16, no. c, pp. 493-496, 2017, doi: 10.1109/LAWP.2016.25856 50.

[26] A. Basir and H. Yoo, "Efficient Wireless Power Transfer System with a Miniaturized Quad-Band Implantable Antenna for Deep-Body Multitasking Implants", IEEE Trans. Microw. Theory Tech., vol. 68 , no. 5, pp. 1943-1953, 2020, doi: 10.1109/TMTT .2020 .2965938 .

27] P. Bose, A. Khaleghi, M. Albatat, J. Bergsland, and I. Balasingham, "RF Channel Modeling for Implant-to-Implant Communication and Implant to Subcutaneous Implant Communication for Future Leadless Cardiac Pacemakers", IEEE Trans. Biomed. Eng., vol. 65, no. 12, pp. 2798-2807, 2018, doi: 10.1109/TBME. 2018.2817690 .

28] H. Liu, J. Shi, S. Wu, X. Wang and J. Wang, "Dual-Band Monopole -Helix Antenna System for MHz-Band Implant Body Area Networks", 2019 IEEE Int. Work. Electromagn. Appl. Student Innov. Compet. iWEM 2019 - Proc., pp. 1-2, 2019, doi: 10.1109/iWEM.2019.8887877.

[29] G. Sun, B. Muneer, Y. Li, and Q. Zhu, "Ultracompact Implantable Design with Integrated Wireless Power Transfer and RF Transmission Capabilities", IEEE Trans. Biomed. Circuits Syst., vol. 12, no. 2, pp. 281-291, 2018, doi: 10.1109/TBCAS.2017.27876 49.

[30] W. Xia, K. Saito, M. Takahashi, and K. Ito, "Performances of an implanted cavity slot antenna embedded in the human arm", IEEE Trans. Antennas Propag., vol. 57, no. 4 Part 1, pp. 894-899, 2009, doi: 10.1109/TAP.2009.2014579.

Received 21 July 2021 